\title{
The genus Drepanolejeunea (Spruce) Schiffn. (Lejeuneaceae; Marchantiophyta) in the Western Ghats with special reference to Kerala
}

\author{
Chandini V K, Mufeed B, Manju C N* \& Rajesh K P \\ Department of Botany, Zamorin's Guruvayurappan College (affiliated to the University of Calicut), Kozhikode 673 014, India \\ *Email:manjucali@gmail.com
}

\section{ARTICLE HISTORY}

Received: 31 March 2020

Accepted: 20 June 2020

Published: 16 August 2020

\section{KEYWORDS}

distribution; description; new

records; taxonomy

\section{ABSTRACT}

Diversity of the genus Drepanolejeunea (Spruce) Schiffn. of the family Lejeuneaceae in Kerala is discussed in detail. So far, 8 species have been reported from the Western Ghats, of which 6 occur in Kerala. This paper provides detailed descriptions of 5 of the species collected from Kerala during the present survey. Among these, Drepanolejeunea erecta (Steph.) Mizut. is new to the Western Ghats, $D$. fleischeri (Steph.) Grolle \& Zhu, D. pentadactyla (Mont.) Steph. and D. ternatensis (Gottsche) Steph. are new records for Kerala.

\section{Introduction}

Drepanolejeunea (Spruce) Schiffn. is a widespread genus in the tropics belonging to the family Lejeuneaceae. The genus was instituted by Spruce (1) as a subgenus of Lejeunea Lib. Schiffner (2) raised it to a genus. Gradstein (3) treated the genus as a separate subtribe Drepanolejeuneinae together with Vitalianthus R.M. Schust. \& Giancotti. However, this is not widely followed. Based on a previous study, divided this genus into 5 subgenera which is also not followed here (4).

Drepanolejeunea is represented in India by 20 species (Table 1). Based on available reports, it appears that the centre of diversity of this genus might be Eastern Himalaya with 11 species closely followed by the Northeast with 10 species.

Reports are on the first record of Drepanolejeuna angustifolia (Mitt.) Grolle and D. ternatensis (Gottsche) Steph. (as D. ternatensis var. lancispina), from the Western Ghats of Tamil Nadu (5). Several species were subsequently reported from Karnataka, Kerala and Tamil Nadu part of the Western Ghats as well which total to 8 species. From Kerala, 6 species have been reported so far (Table 1).
The present survey reports a total of 5 species distributed in Kerala namely Drepanolejeuna angustifolia (Mitt.) Grolle, $D$. erecta (Steph.) Mizut., $D$. fleischeri (Steph.) Grolle \& Zhu, D. pentadactyla (Mont.) Steph. and D. ternatensis (Gottsche) Steph. Of these, $D$. erecta (Steph.) Mizut. is a new record for the Western Ghats and D. fleischeri (Steph.) Grolle \& Zhu, D. pentadactyla (Mont.) Steph. and $D$. ternatensis (Gottsche) Steph. are new records for Kerala. Detailed descriptions of the 5 species along with photo plates and illustrations are provided here. World distribution and distribution within the Western Ghats are mapped (Map 1A \& 1B).

\section{Results and Discussion}

Key to the species of Drepanolejeunea in the Western Ghats

1a. Leaves linear-lanceolate 2

1 b. Leaves ovate or oblong 3

2a. Leaves caducous, involute at apex, serrate at margin, with 1 or 2 teeth; teeth 2 - or 3-celled D. ternatensis

(C) Chandini et al (2020). This is an open-access article distributed under the terms of the Creative Commons Attribution License, which permits unrestricted use, distribution, and reproduction in any medium, provided the original author and source are credited (https://creativecommons.org/licenses/by/4.0/)

To cite this article: Chandini V K, Mufeed B, Manju C N, Rajesh K P. The genus Drepanolejeunea (Spruce) Schiffn. (Lejeuneaceae; Marchantiophyta) in the Western Ghats with special reference to Kerala. Plant Science Today. 2020;7(3):483-500. https://doi.org/10.14719/pst.2020.7.3.789 
Table 1. Diversity and distribution of Drepanolejeunea (Spruce) Schiffn. in India

\begin{tabular}{|c|c|c|c|c|}
\hline Sl. No. & Name of the species & Discovered in India by & $\begin{array}{l}\text { Place of discovery in } \\
\text { India }\end{array}$ & Distribution in India \\
\hline 1. & $\begin{array}{l}\text { Drepanolejeunea angustifolia (Mitt.) } \\
\text { Grolle }\end{array}$ & Mitten, 1861 (7) & Eastern Himalaya & $\begin{array}{l}\text { Andaman \& Nicobar } \\
\text { Isl., E. Himalaya and W. } \\
\text { Ghats (Kerala \&Tamil } \\
\text { Nadu) }\end{array}$ \\
\hline 2. & D. dactylophora (Nees et al.) Schiffn. & Daniels \& Kariyappa (42) & Western Ghats & W. Ghats (Tamil Nadu) \\
\hline 3. & D. devendrae S.K. Singh \& M. Dey & Singh \& Dey (43) & Northeast India & NE. India \\
\hline 4. & D. erecta (Steph.) Mizut. & Udar \& Awasthi (7) & Eastern Himalaya & $\begin{array}{l}\text { E. Himalaya, NE. India } \\
\text { and W. Ghats (Kerala*) }\end{array}$ \\
\hline 5. & D. fleischeri (Steph.) Grolle et R.-L. Zhu & Asthana \& Shukla (31) & Western Ghats & $\begin{array}{l}\text { E. Himalaya, NE. India } \\
\text { and W. Ghats } \\
\text { (Karnataka \& Kerala*) }\end{array}$ \\
\hline 6. & D. foliicola Horik. & Pandé et al. (43) & Eastern Himalaya & $\begin{array}{l}\text { E. Himalaya, NE. India } \\
\text { and W. Ghats (Kerala \& } \\
\text { Tamil Nadu) }\end{array}$ \\
\hline 7. & D. herzogii R.-L. Zhu et M.L. So & Dey et al. (27) & Eastern Himalaya & $\begin{array}{l}\text { E. Himalaya and NE. } \\
\text { India }\end{array}$ \\
\hline 8. & D. laciniata Q. He et R.-L. Zhu & Singh (9) & Eastern Himalaya & E. Himalaya \\
\hline 9. & D. longii Grolle et R.-L. Zhu & Dey \& Singh (18) & Eastern Himalaya & E. Himalaya \\
\hline 10. & D. mawtmiana A.P. Singh et V. Nath & Singh \& Nath (16) & Northeast India & NE. India \\
\hline 11. & D. mizoramensis S.K. Singh & Singh (44) & Northeast India & NE. India \\
\hline 12. & D. pentadactyla (Mont.) Steph. & Asthana \& Shukla (31) & Western Ghats & $\begin{array}{l}\text { Andaman \& Nicobar Isl. } \\
\text { and W. Ghats } \\
\text { (Karnataka \& Kerala*) }\end{array}$ \\
\hline 13. & D. pulla (Mitt.) Grolle & Mitten, 1861 (17) & Eastern Himalaya & E. Himalaya \\
\hline 14. & D. siamensis (Bischl.) Grolle et R.-L. Zhu & Dey \& Singh (18) & Eastern Himalaya & E. Himalaya \\
\hline 15. & D. spicata (Steph.) Grolle et R.-L. Zhu & Grolle \& R.-L. Zhu (45) & Northeast India & NE. India \\
\hline 16. & D. ternatensis (Gottsche) Steph. & Udar \& Awasthi (7) & Western Ghats & $\begin{array}{l}\text { W. Ghats (Kerala* \& } \\
\text { Tamil Nadu) }\end{array}$ \\
\hline 17. & D. thwaitesiana (Mitt.) Steph. & Dey et Singh (36) & $\begin{array}{l}\text { Andaman \& Nicobar } \\
\text { Islands }\end{array}$ & Andaman \& Nicobar Isl. \\
\hline 18. & $\begin{array}{l}\text { D. tibetana (P.C. Wu et J.S. Lou) Grolle et } \\
\text { R.-L. Zhu }\end{array}$ & Dey \& Singh (18) & Eastern Himalaya & E. Himalaya \\
\hline 19. & D. vesiculosa (Mitt.) Steph. & Udar \& Awasthi (7) & Northeast India & NE. India \\
\hline 20. & $\begin{array}{l}\text { D. yunnanensis (P.C. Chen) Grolle et R.-L. } \\
\text { Zhu }\end{array}$ & Udar \& Awasthi (46) & $\begin{array}{l}\text { Western Ghats/ Eastern } \\
\text { Himalaya }\end{array}$ & $\begin{array}{l}\text { E. Himalaya, NE. India } \\
\text { and W. Ghats } \\
\text { (Karnataka) }\end{array}$ \\
\hline
\end{tabular}

* Present study

2b. Leaves not caducous, not involute at apex, entire at margin D. angustifolia

3a. Leaves irregularly toothed at margin with 3 to 8 teeth ..... 4

3b. Leaves entire at margin 5

4a. Leaf lobules $1 / 2$ to $3 / 4$ as long as leaf, 2-toothed at apex; first tooth large, hooked ............................................ D. pentadactyla

4b. Leaf lobules $2 / 3$ as long as leaf, 2-toothed at apex; first tooth neither large nor hooked. D. dactylophora

5a. Underleaf sinus 3 to 5 times as wide as stem; free lateral margin of leaf lobule bordered by more than 5 rectangular cells ... 6

5b. Underleaf sinus twice as wide as stem; free lateral margin of leaf lobule bordered by 4 rectangular cells 6a. Leaf lobules $1 / 2$ to more than half as long as leaf; first tooth of lobule cell curved like a hook....... 7

$6 \mathrm{~b}$. Leaf lobules not more than $1 / 2$ as long as leaf; first tooth of lobule not curved like a hook................................................ foliicola

7a. Leaf loule1/2-3/4 as long as the leaf lobe, lobes of the lobule uniseriate at extreme tip with 3-4 cells long

D. fleischeri

7b. Leaf lobule $2 / 5$ as long as the leaf lobe, lobes of the lobule linear, uniseriate with 6-9 cells long. .D. yunnanensis

Drepanolejeunea angustifolia (Mitt.) Grolle, J. Jap. Bot. 40: 206. 1965; Udar \& U.S.Awasthi, J. Hattori Bot. Lab. 53: 420. 1982; Manju et al., Trop. Bryol. Res. Rep. 7: 4. 2008; A.E.D.Daniels, Arch. Bryol. 65. 2010; A.E.D. Daniels \& P.Daniel, Bryofl. S. W. Ghats. India: 147. 2013; Manju et al., Act. Biol. Plant. Agri. 2: 132. 2012; M.Dey \& D.K. Singh, Epiphyll. Liverw. E. Himal.: 216. 


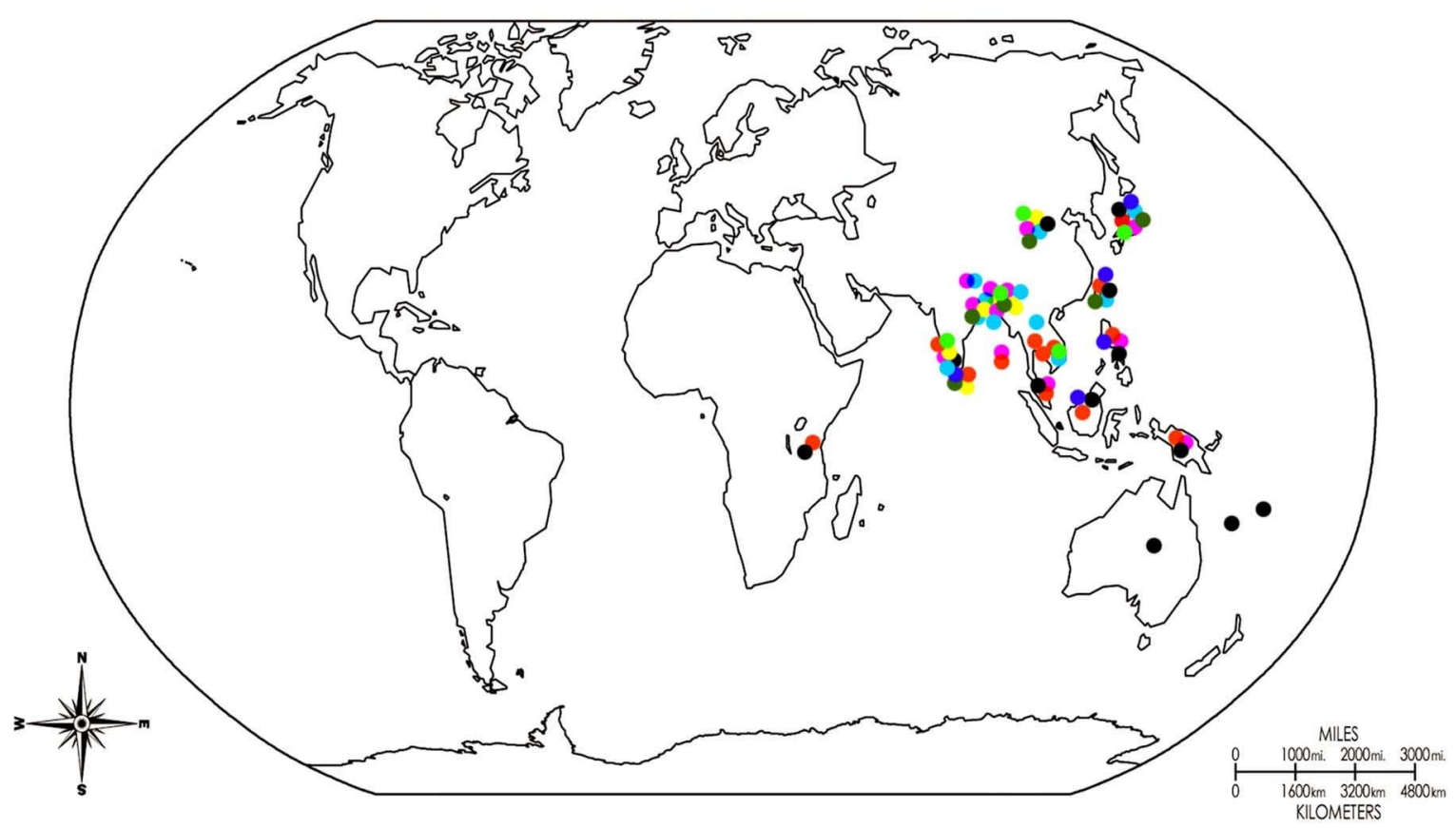

Map 1A. World distribution of the Genus Drepanolejeunea
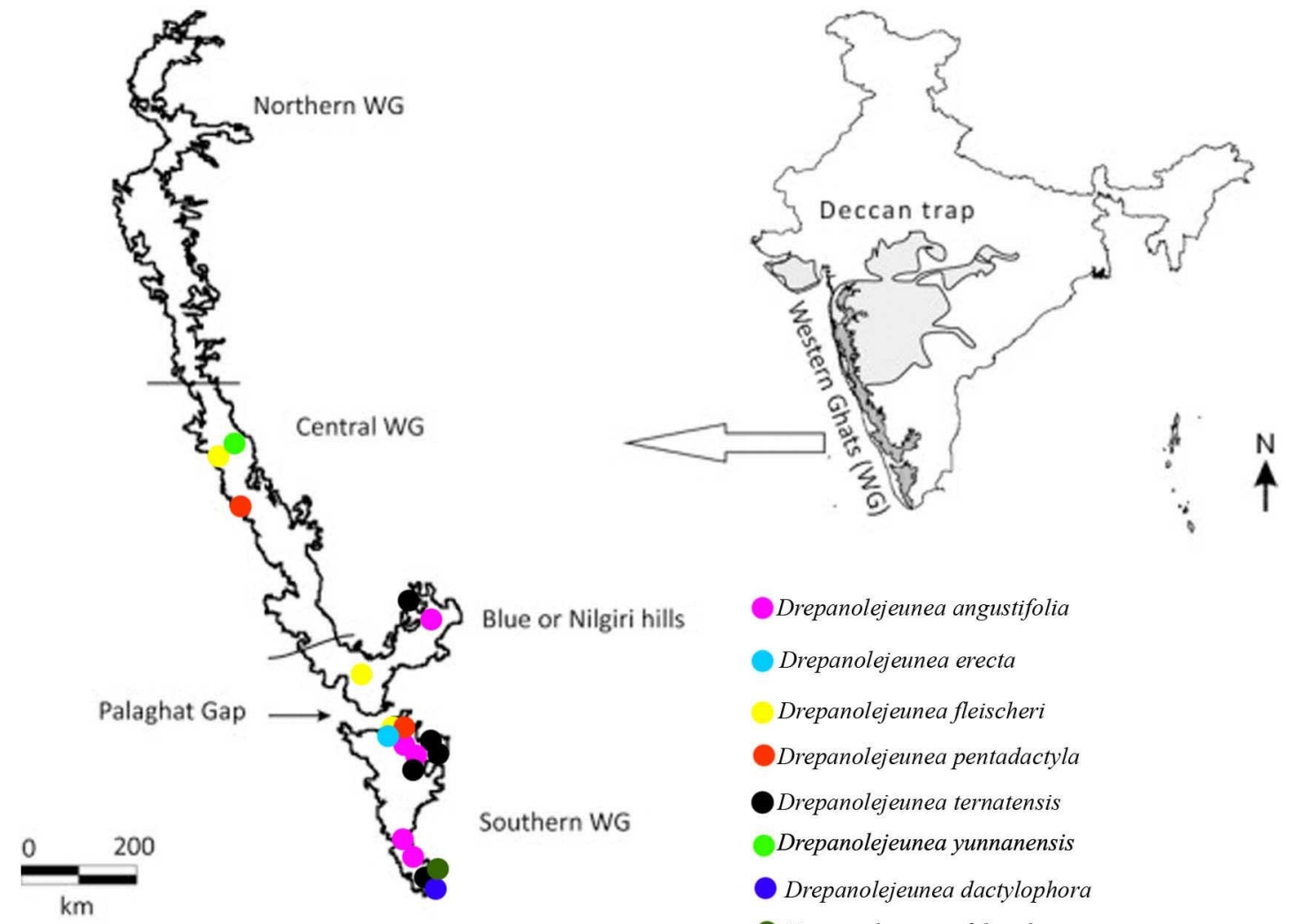

Map 1. B Distribution of the Genus Drepanolejeunea and distribution in Western Ghats

2012; M. Dey et al., Trop. Bryol. 35: 15. 2013; D.K.Singh et al., Liverw. \& Hornw. India, 134: 2016; A.E.D.Daniels \& Kariyappa, Bryo. Agasthyamalai Bio. Res.: 485. 2019. Jungermannia tenuis Reinw., Blume \& Nees, Nova Acta Acad. Caes. Leop.- Carol. German.
Nat. Cur. 12: 226. 1824. Lejeunea angustifolia Mitt., J. Proc. Linn. Soc., Bot. 5: 116. 1861. Drepanolejeunea tenuis (Reinw., Blume \& Nees) Schiffn., Consp. Hepat. Arch. Ind. 280. 1898; Mizutani, J. Hattori Bot. Lab. 26: 172.1963; Udar \& Awasthi, J. Hattori Bot. Lab. 53: 420. 
1982. Physocolea angustifolia (Mitt.) Steph., Sp. Hepat.5: 887.1916. Drepanolejeunea longifolia A.P. Singh \& V. Nath, Hepat. Khasi Jaintia Hills: E. Himal. 248. 2007.

Type: India, Sikkim, J.D. Hooker 1498 (BM).

Plants pale green when fresh and brownish when dry, 4-10 × 0.31-0.35 mm including leaves, branched; stem in transverse section with 7 cortical cells, $10-15 \times 12-14 \mu \mathrm{m}, 4$ medullary cells, $4-8 \times 6-9 \mu \mathrm{m}$ diagonally, ventral merophytes 2 cells wide; rhizoids present at the base of underleaves, numerous, tufted, hyaline; rhizoidal disc absent; leaves distant, diverging from stem at an angle of $30-40^{\circ}$; leaf lobe linear-lanceolate, erect-spreading, $0.28-0.30 \times 0.09$ $0.13 \mathrm{~mm}$; apex acute, ending in a single cell; margin slightly serrulate, arched dorsally, straight ventrally; cells at margin polygonal, 11-23 $\mu \mathrm{m}$; median cells rounded to polygonal, $20-25 \times 10-13 \mu \mathrm{m}$; basal cells hexagonal, polygonal, 18-20 × 10-15 $\mu \mathrm{m}$; trigones and intermediate nodular thickenings absent; cells smooth; oil bodies and ocelli not seen; leaf lobule inflated, $1 / 2$ as long as leaf lobe, ovate, $0.10-0.16 \times 0.10$ $0.11 \mathrm{~mm}$, bilobed; first tooth unicellular, elongate, curved; second tooth indistinct; free lateral margin bordered by 4 linear cells; keel arched; underleaves distant, small, as wide as stem, bilobed, sinus Vshaped, 0.04-0.08 × 0.06-0.07 mm; lobes uniseriate, 2-3 cells long, 2 cells wide at base; reproductive structures not seen (Fig. 1 \& 2).

Specimens examined: India, Kerala, Idukki, Anamudi shola NP, Mannavan shola, Idalimotta (2200 m, 1011'40”N 77010’31”E), 25.09.2018, Mufeed 9972, 10018c (ZGC); Eravikulam NP, Amarshola (2000 m, $10^{0} 10^{\prime} 45^{\prime}$ N 77005'26”E), 23.10.2001 Manju C.N. 80241/ b (CALI!).

\section{Habitat: Epiphytic on tree trunk.}

Distribution: World: Bhutan (6), China (7), Japan (8), Malaysia (9), Nepal (10), Papua New Guinea (11), Philippines (12). India: Andaman (13, 14), Arunachal Pradesh (15), Meghalaya (16), Sikkim (17 as L. angustifolia, 18), West Bengal (5 \& 19 as D. tenuis) Western Ghats; [Tamil Nadu; Nilgiri BR, Doddabetta (5), Kanyakumari, Upper Kodaiyar (20), Kerala; Idukki, Eravikulam NP, Amarshola (21, 22), Anamudi shola National Park, Idalimotta (Present study)].

Drepanolejeunea erecta (Steph.) Mizut., J. Hattori Bot. Lab. 40: 442. 1976; A.P.Singh \& V.Nath Hepat. Khasi Jaintia Hills: E. Himal: 250 2007; M.Dey \& D.K. Singh, Epiphyll. Liverw. E. Himal. 219. 2012; M. Dey et al., Trop. Bryol. 35: 16. 2013; D.K. Singh et al., Liverw. \& Hornw. India, 134: 2016. Leptolejeunea erecta Steph., Bull. Soc. Roy. Bot. Belgique 38: 44. 1899; Stephani, Sp. Hep. 1044. 1913 Strepsilejeunea monophthalma Herzog in Hand.- Mazz., Symb. Sin. 5:47. 1930. Drepanolejeunea monophthalma (Herzog) Mizut., J. Hattori Bot. Lab. 29: 291.1996; Hattori, Fl. East. Himalaya, 501- 536: 1966.

Type: India, Darjeeling, 1894, Stevens 509 HolotypeG-14859.

Plants yellowish green in fresh, yellowish brown when dried, stem 5-15 × 0.57-0.70 mm including leaves, branched, irregular, stem in transverse section with 7 cortical cells $13-23 \mu \mathrm{m}, 4$ medullary cells, small, 13-17 $\mu \mathrm{m}$, slightly thick walled, ventral merophytes 2 cells wide; rhizoids tufted at the base of under leaves, hyaline, rhizoidal disc present; leaves contiguous, obliquely spreading, diverging from stem at $32-42^{\circ}$ angle, leaf lobe ovate oblong, 0.28-0.32 $\times$ 0.12-0.20 mm, apex subacute, margin crenulate due to papillae, dorsal margin arched, concave, ventral margin slightly arched, leaf cells thick walled, cuticle present, trigones and intermediate nodular thickening present, leaf marginal cells rectangular, elongated, 7-14 × 3- $7 \mu \mathrm{m}$, median cells polygonal, 6.5$17.6 \times 3-7 \mu \mathrm{m}$, basal cells elongated, rectangular, 19$26 \times 4.90-6.00 \mu \mathrm{m}$, ocelli 1-2 per cells; leaf lobule inflated, $1 / 3-1 / 2$ as long as the leaf lobe, $0.10-0.15 \times$ 0.06-0.07 $\mathrm{mm}$, oblong ovate, bidentate, first tooth unicellular, curved, 28-35 × 6-10 $\mu \mathrm{m}$, proximal hyaline cell at the tip of first tooth, second tooth indistinct, free lateral margin bordered by 4 linear rectangular cells, keel arched, smooth; underleaves distant, $0.8-0.12 \times 0.6-0.8 \mathrm{~mm}$, bilobed, uniseriate lobes, 4-6 cells long, 4 cells wide at base, uniseriate above, lamina composed of 6-7 cells surrounding numerous rhizoidal initial cells, twice wider than stem, spreading at $43-83^{\circ}$ angle with stem, similar with Leptolejeunea type, ie, the underleaves with uniseriate lobes and rhizoidal discs shown in genus Leptolejeunea in some of the underleaves. Asexual and Sexual reproductive structures are not observed. (Fig. 3-5).

Specimens examined: India, Kerala, Kollam, Shenduruni WLS, Pandimotta (1300 m, 8049'05”N 77013'52”) 22.09.2019 Chandini 10785c, 10786, 10791 (ZGC).

Habitat: Epiphyllous, growing along with Cololejeunea ocellata (Horik.) Benedix, Cololejunea haskarliana (Lehm. \& Lindenb.) Schiffn., Lejeunea tuberculosa Steph. and Lejeunea exilis (Reinw. et al.) Grolle.

Distribution: World; Bhutan (6), China (7), Japan (23), Laos (24), Nepal (25), Taiwan (26), Vietnam (24).

India; Assam (18), Arunachal Pradesh (18, 27), Manipur (28), Meghalaya (5, 16), Sikkim (9, 13, 18, 29, as D. monophthalma, as Leptolejeunea erecta; (5), West Bengal (29 as D. monophthalma, 18), Western Ghats; (Kerala, Present study). Present study records this species for the first time from the Western Ghats.

Drepanolejeunea fleischeri (Steph.) Grolle \& R. L. Zhu, Nova Hedwigia 70: 379. 2000; A.K. Astahana \& Shukla, J. Bryol. 31: 139: 2009; M. Dey \& D.K. Singh, Epiphyll. Liverw. E. Himal.: 223. 2012; D.K. Singh et al., Liverw. \& Hornw. India: 135: 2016. Leptolejeunea fleischeri Steph., Sp. Hepat. 5: 382. 1913.

Type: Sri Lanka, Fleischer 2024 (Lectotype- G-11858).

Plant light green in fresh, yellowish brown when dried, stem 5-10 × 0.6-1.2 mm including leaves, branched, irregular, stem in transverse section with 7 cortical cells, 4 small medullary cells, slightly thick walled, ventral merophytes 2 cells wide; rhizoids tufted at the base of underleaves, hyaline, rhizoidal disc absent; leaves contiguous, imbricate, obliquely spreading, leaf lobe oblong ovate, 0.30-0.60 × 0.2-0.35 $\mathrm{mm}$, apex acute, margin denticulate, dorsal margin 

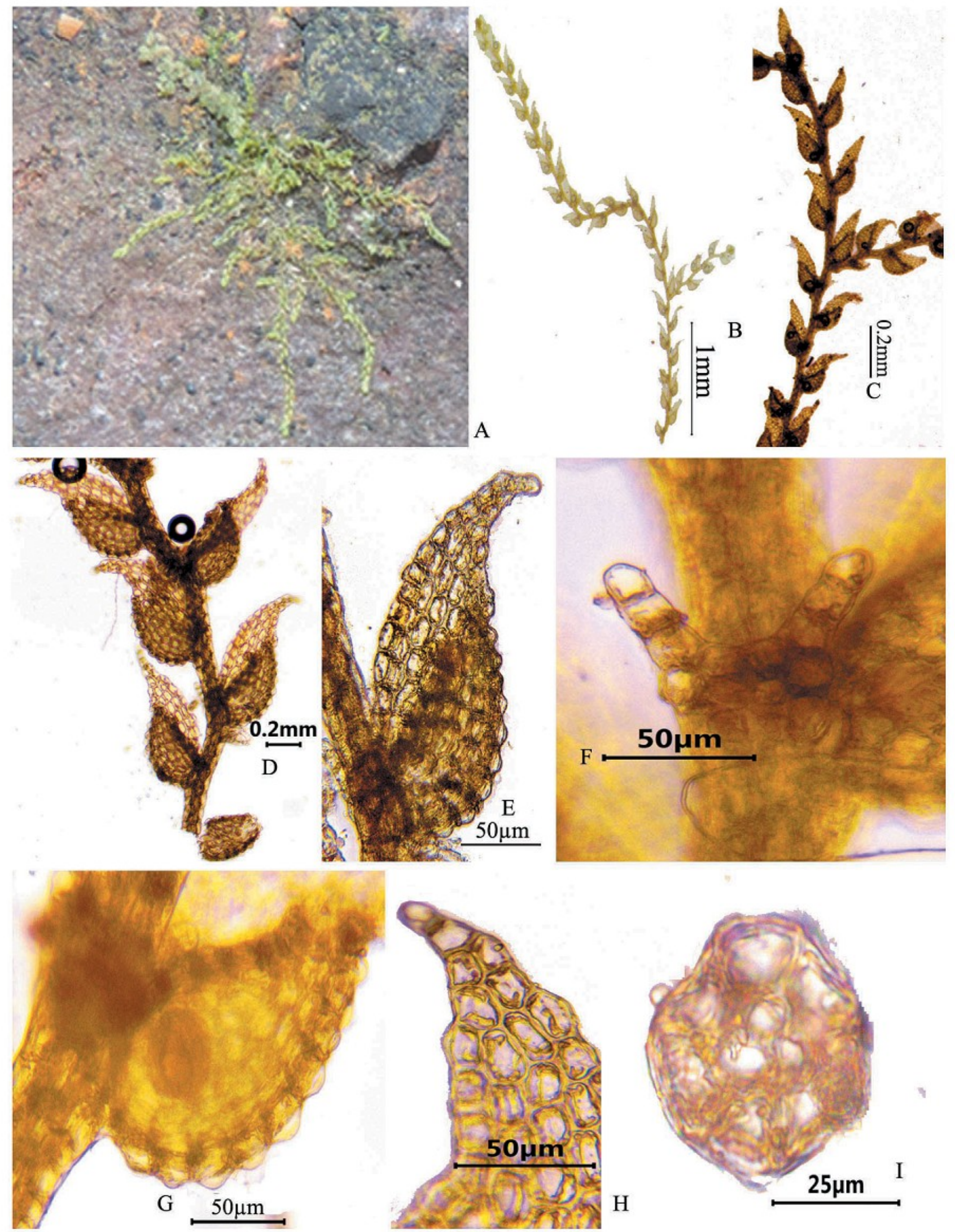

Fig. 1 (A-I). Drepanolejeunea angustifolia (Mitt.) Grolle, A. habit, B. single plant, C \& D. branch enlarged view, E. leaf with lobule, F. underleaf, G. leaf lobule, H. leaf tip cells, I. C. S. of stem.

arched, ventral margin almost straight, apical leaf cells quadrate to sub quadrate, polygonal, 4-8 × 5-7 $\mu \mathrm{m}$, median cells hexagonal, $9-22 \times 10-16 \mu \mathrm{m}$, basal cells large, polygonal, 17-36 $\mu \mathrm{m}$, leaf cells thin walled, trigones small or indistinct, ocelli 1-2 per cells, oil bodies single and clustered, 5-10 in number; leaf lobule; inflated, $1 / 2-3 / 4$ as long as the leaf lobe, ovate, $0.08-0.15 \mathrm{~mm}$ long, $0.30-0.34 \mathrm{~mm}$ wide, 2 toothed, 


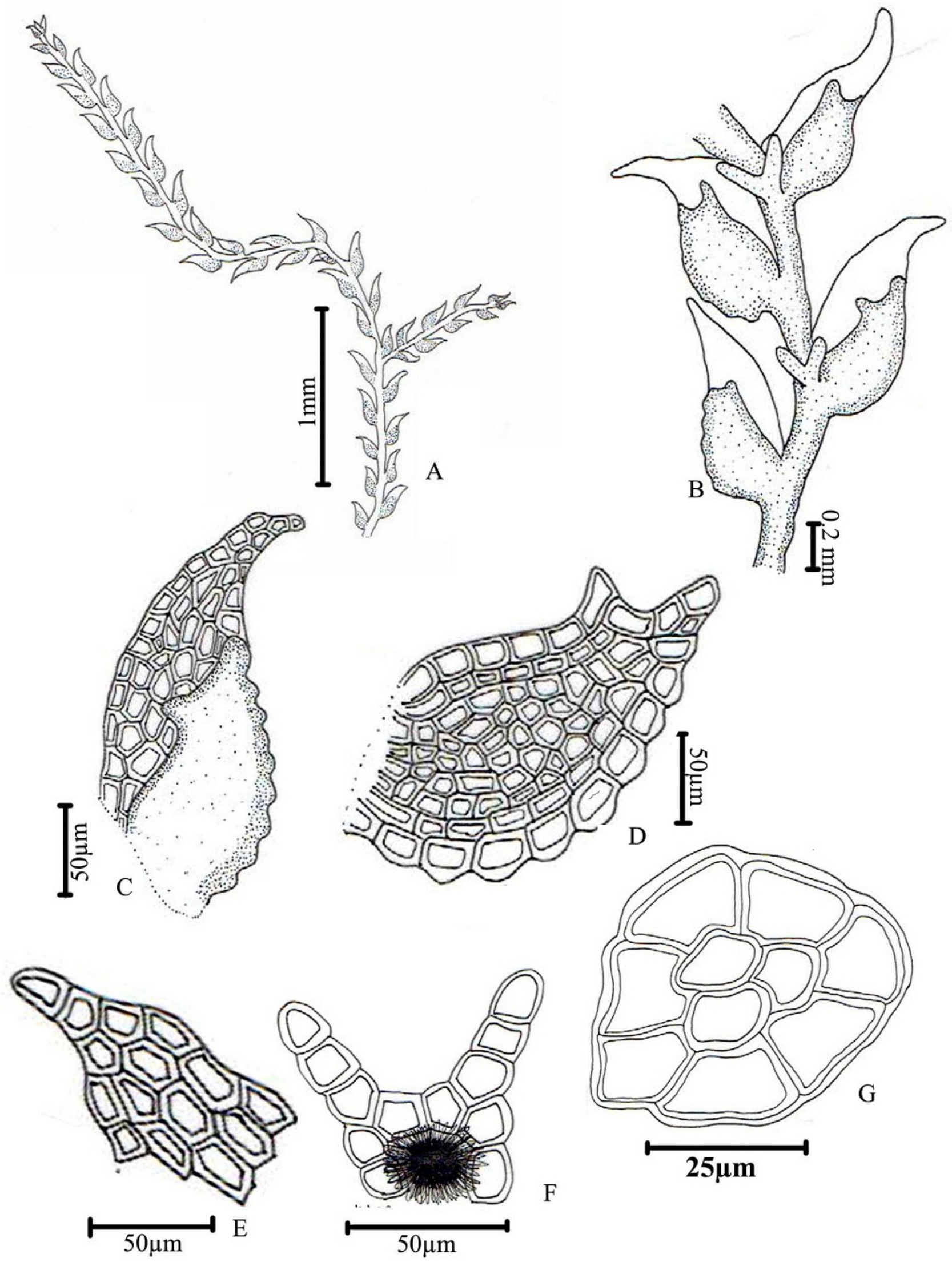

Fig. 2 (A-G). Drepanolejeunea angustifolia (Mitt.) Grolle, A. portion of plant, B. a portion of stem ventral view, C. single leaf, D. leaf lobule, E. cells at leaf apex, F. underleaf, G. stem C.S.

first tooth unicellular, strongly curved like a hook, 20$24 \mu \mathrm{m}$ long, second tooth unicellular, hyaline papilla at the proximal side of first tooth, free lateral margin bordered by 7-10 linear rectangular cells, keel arched, smooth, trigones minute; underleaves distant, 0.16-0.2 $\times 0.11-0.18 \mathrm{~mm}$, bilobed, sinus 5 times wider than stem, uniseriate at extreme tip, 3-4 cells long, biseriate below, 5-6 cells long, 4 cells wide at base, 

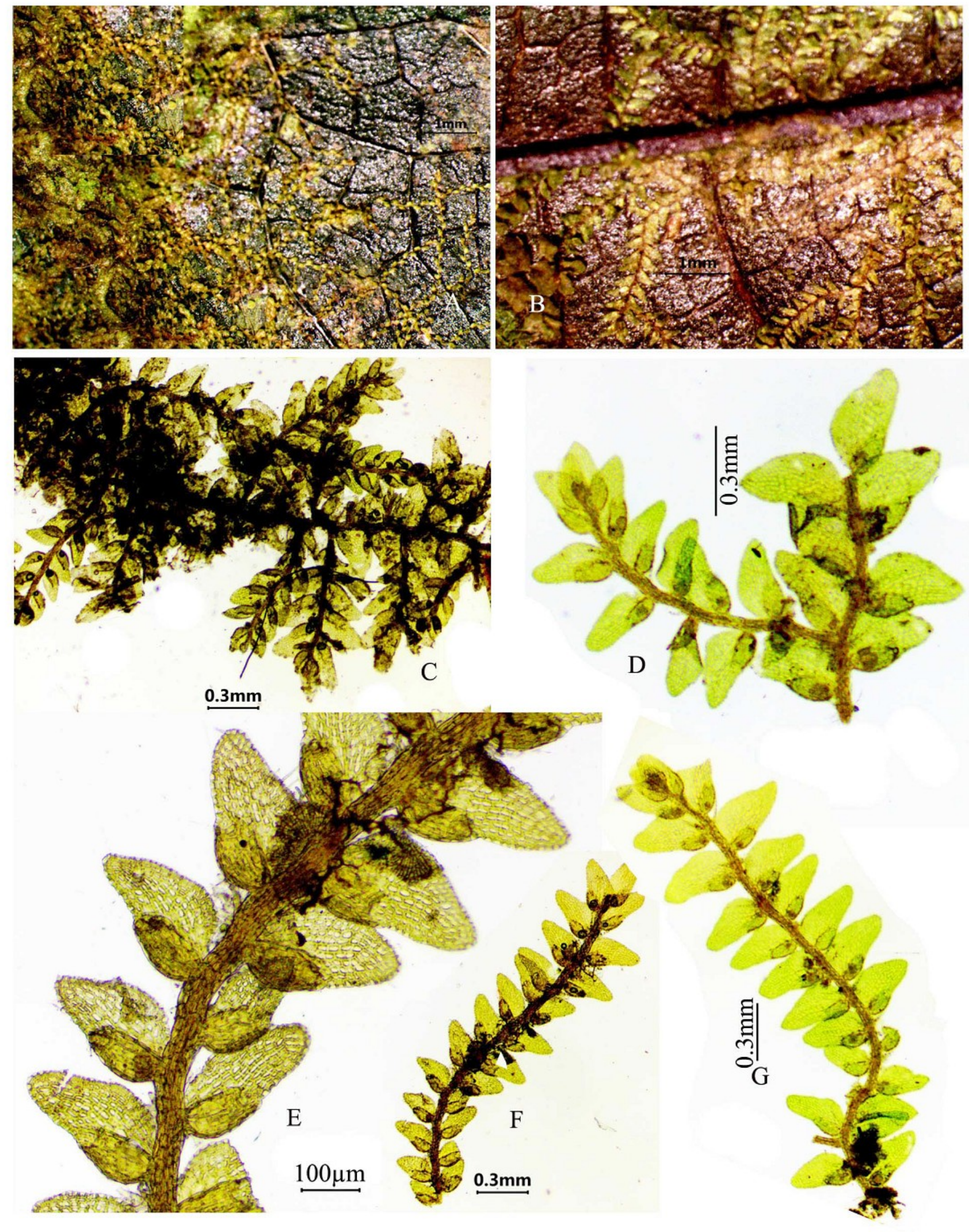

Fig. 3 (A-E). Drepanolejeunea erecta (Steph.) Mizut., A \& B. thallus on leaf surface, C. branched thallus separated from leaf surface, D, F \& G. single branch enlarged, E. enlarged view of portion of thallus.

cells rectangular to hexagonal, perianth on short lateral branches without innovations, perianth sharply 5 plicate with horizontal, triangular shaped horns, androecia not seen, mature sporophytes, asexual reproductive structures not observed (Fig. 6 \& 7).
Specimens examined: India, Kerala, Wayanad, Meppadi, (850 m,- 11033'18”N 76011'09”'E) 04.05.2017 K.P. Rajesh 10230, 10238 (ZGC); Palakkad, Parambikulam Tiger Reserve, Karimala (1110 m, $10^{0} 27^{\prime} 59^{\prime \prime N} 76^{0} 53^{\prime} 42$ ”E) 05.12.2019 Chandini \& Sajitha $11032 b(Z G C)$. 

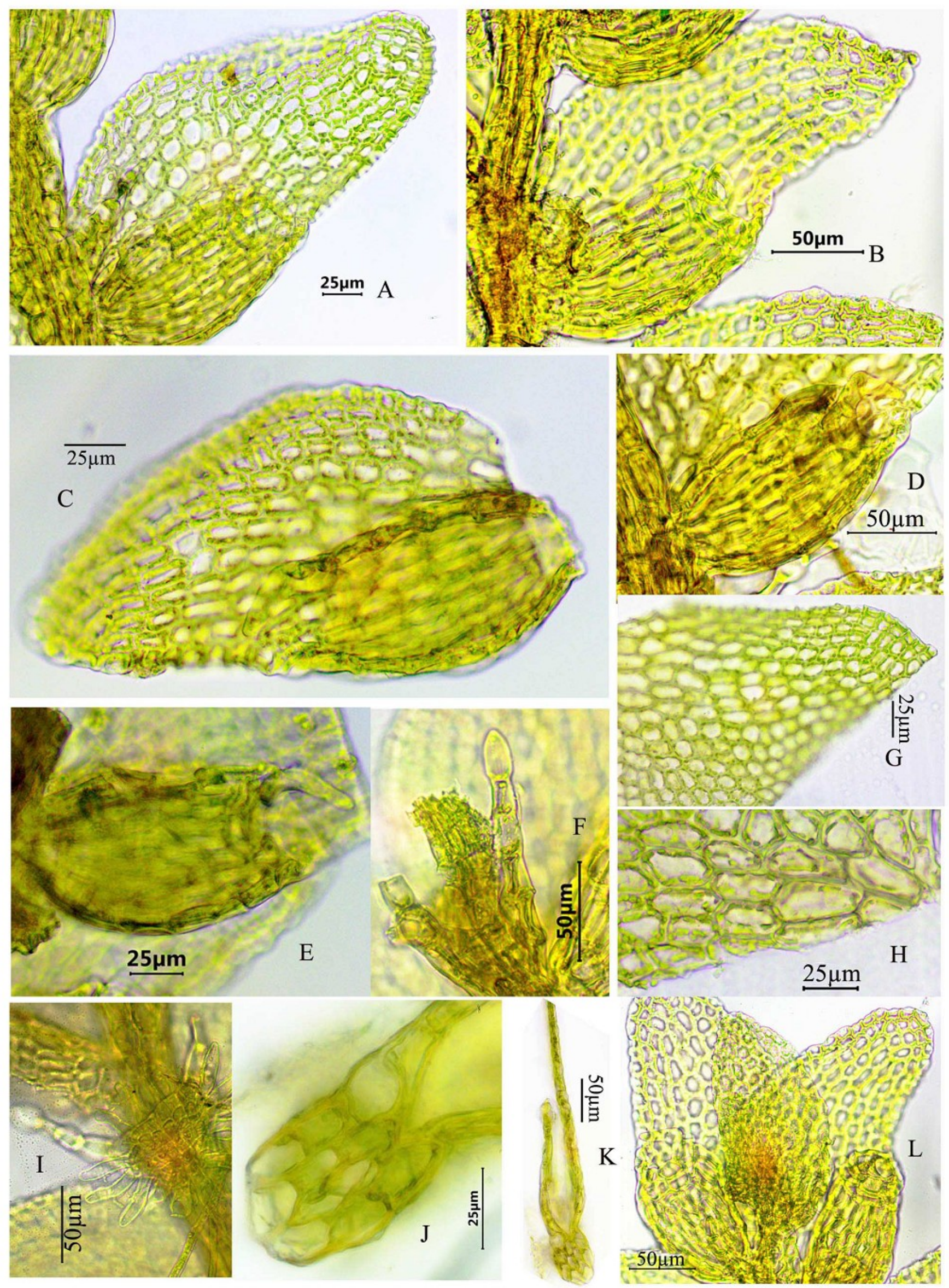

Fig. 4 (A-L). Drepanolejeunea erecta (Steph.) Mizut., A \& B. leaf attached to stem, C. leaf lobe with lobule, D \& E. lobule enlarged view, F \& I. under leaves, G. leaf tip cells, H. leaf basal cells, J. C. S. of stem, K. C. S. of stem and leaf, L. branch tip. 


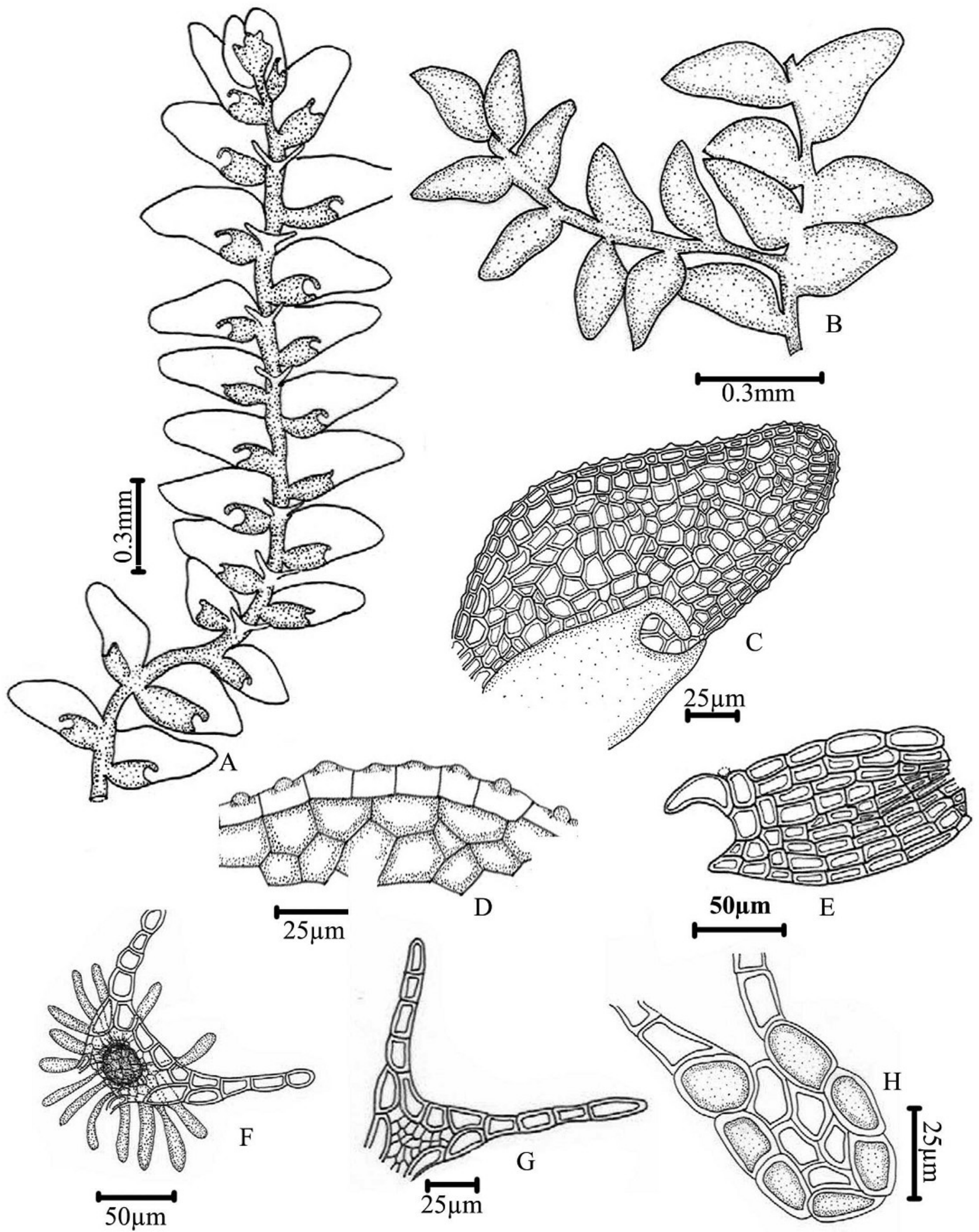

Fig. 5 (A-H) . Drepanolejeunea erecta (Steph.) Mizut., A. plant ventral view, B. branch dorsal view, C. single leaf, D. leaf marginal cells, E. leaf lobule, F . underleaf with rhizoids, G. underleaf, H. stem C. S.

Habitat: Epiphyllous on leaves of angiosperm tree and fronds of Hymenophyllum sp. growing along with Cololejeunea truncatifolia (Horik.) Mizut., Drepanolejeunea pentadactyla (Mont.) Steph. and Leptolejeunea latifolia (Herzog) R. M. Schust.
Distribution: World; China (24), Sri Lanka (30), India; Arunachal Pradesh, Sikkim, West Bengal, Meghalaya $(9,18)$ Western Ghats; Karnataka, Kudremukh, (31); Kerala, Wayanad, Palakkad (Present collections). 

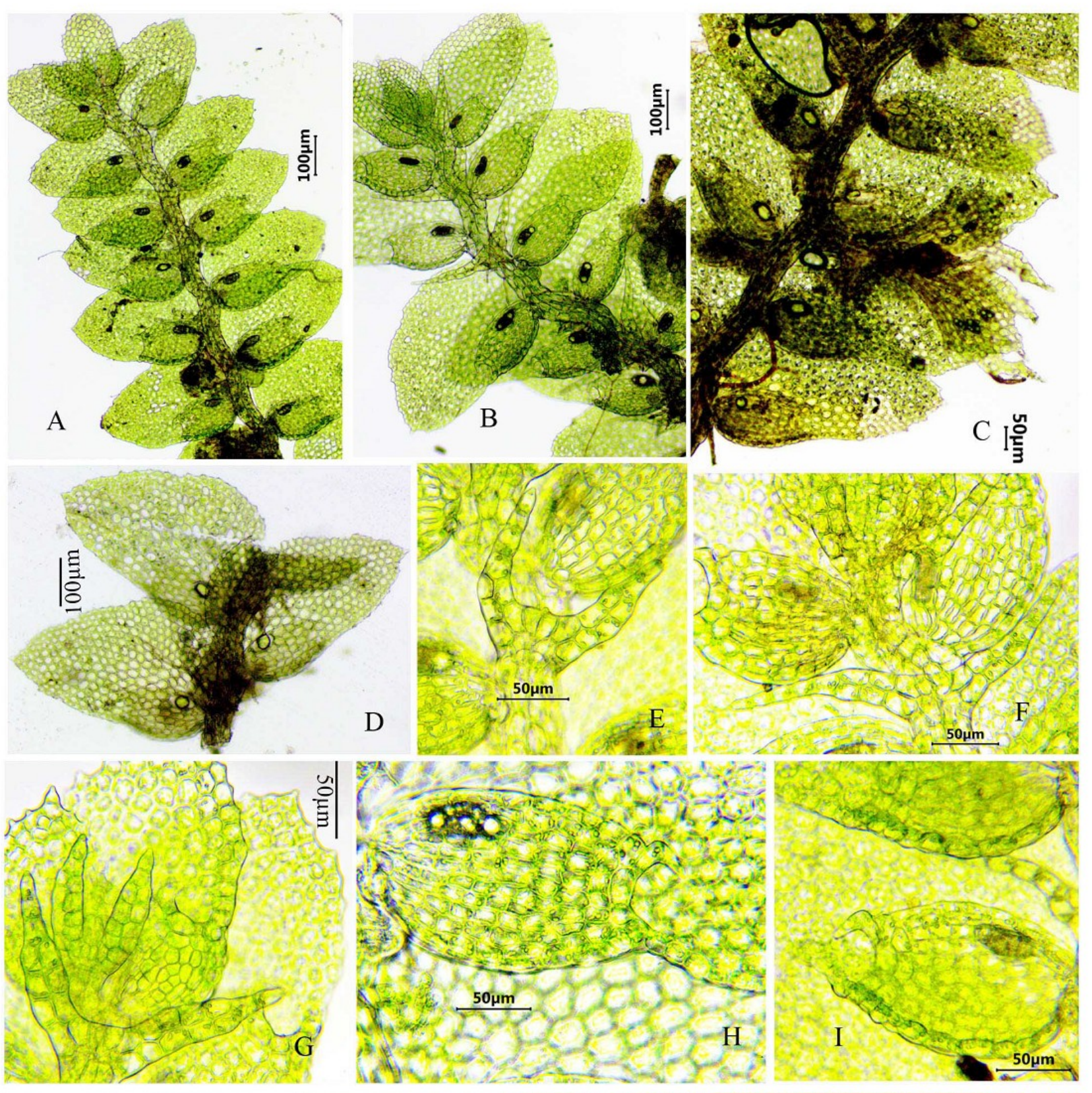

D
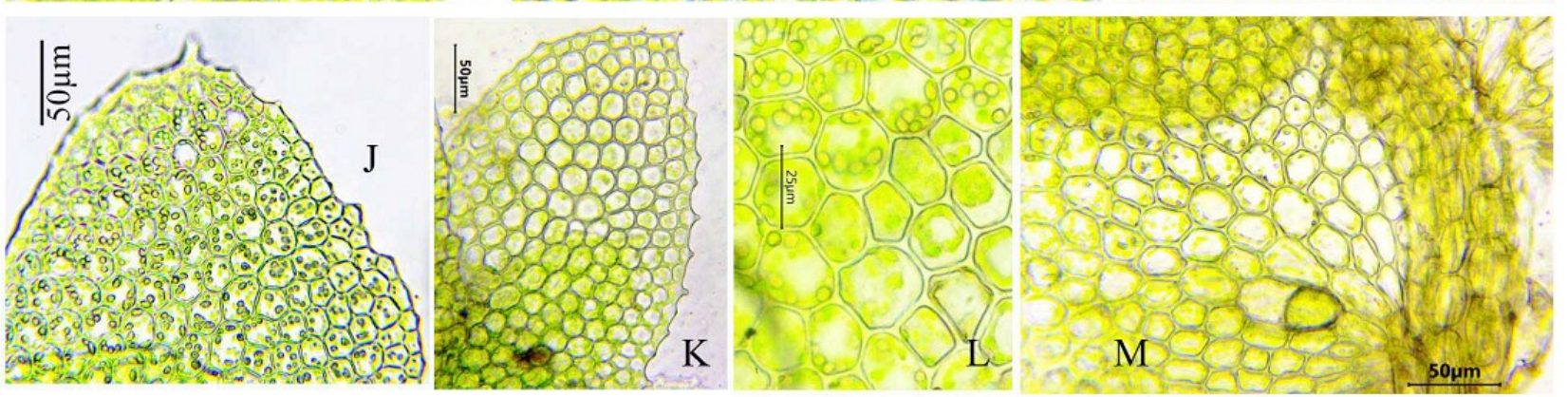

Fig. 6 (A-M). Drepanolejeunea fleischeri (Steph.) Grolle \& R. L. Zhu, A \& B. a portion of plant ventral view, C. plant with perianth, D. leaf arrangement, E \& F. under leaves, G. plant apex with underleaves, H \& I. leaf lobule, J \& K. leaf apex, L. leaf cells with oil bodies, M. leaf basal cells.

Drepanolejeunea pentadactyla (Mont.) Steph., Spec. Hepat. 5: 357. 1913; A.K. Astahana \& Shukla, J. Bryol. 31: 142: 2009; M. Dey \& D.K. Singh Trop. Bryol. 35: 19. 2013; D.K. Singh et al., Liverw. \& Hornw. India 136: 2016. Lejeunea pentadactyla Mont., Ann. Sci. Not., Bot., Ser.3, 10: 113. 1848. Drepanolejeunea micholitzii Steph., Sp. Hepat. 5: 347. 1913. D. chiponensis Horik., J. Sci. Hiroshima Univ., Ser. B, Div.
2: 262. 1934. D. tenuioides Horik., J. Sci. Hiroshima Univ., Ser. B, Div. 2, Bot. 2: 262. 1934.

Type: Tahiti. Coll.: Lepin (s.n.), s.d. Holotype: PC.

Plants green to yellowish when fresh, golden brownish when dry, 4-10 × 0.24-0.3 mm including leaves, branched, vegetative branches $1-3 \mathrm{~mm}$ long, stem in transverse section with seven cortical cells 

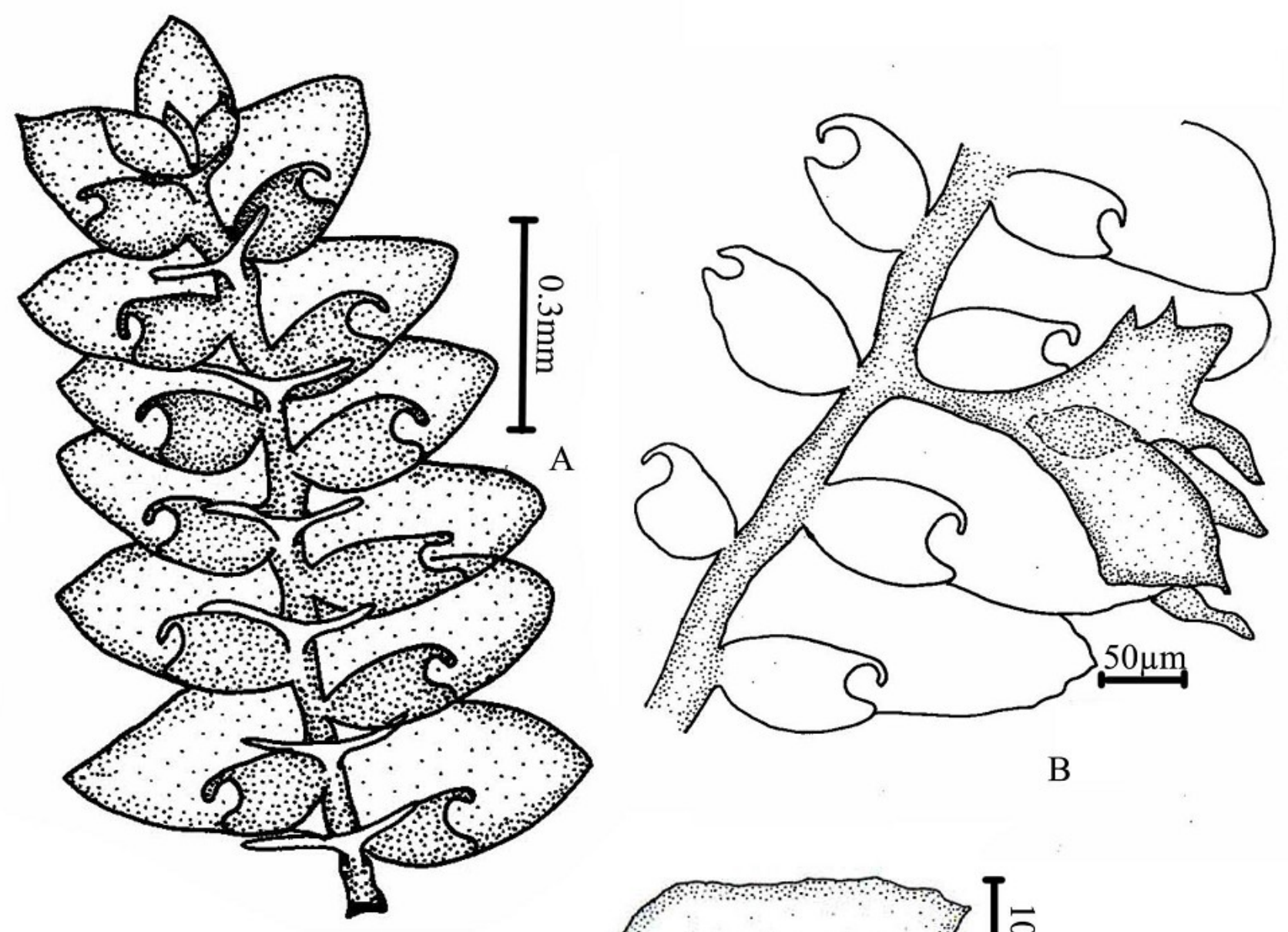

B
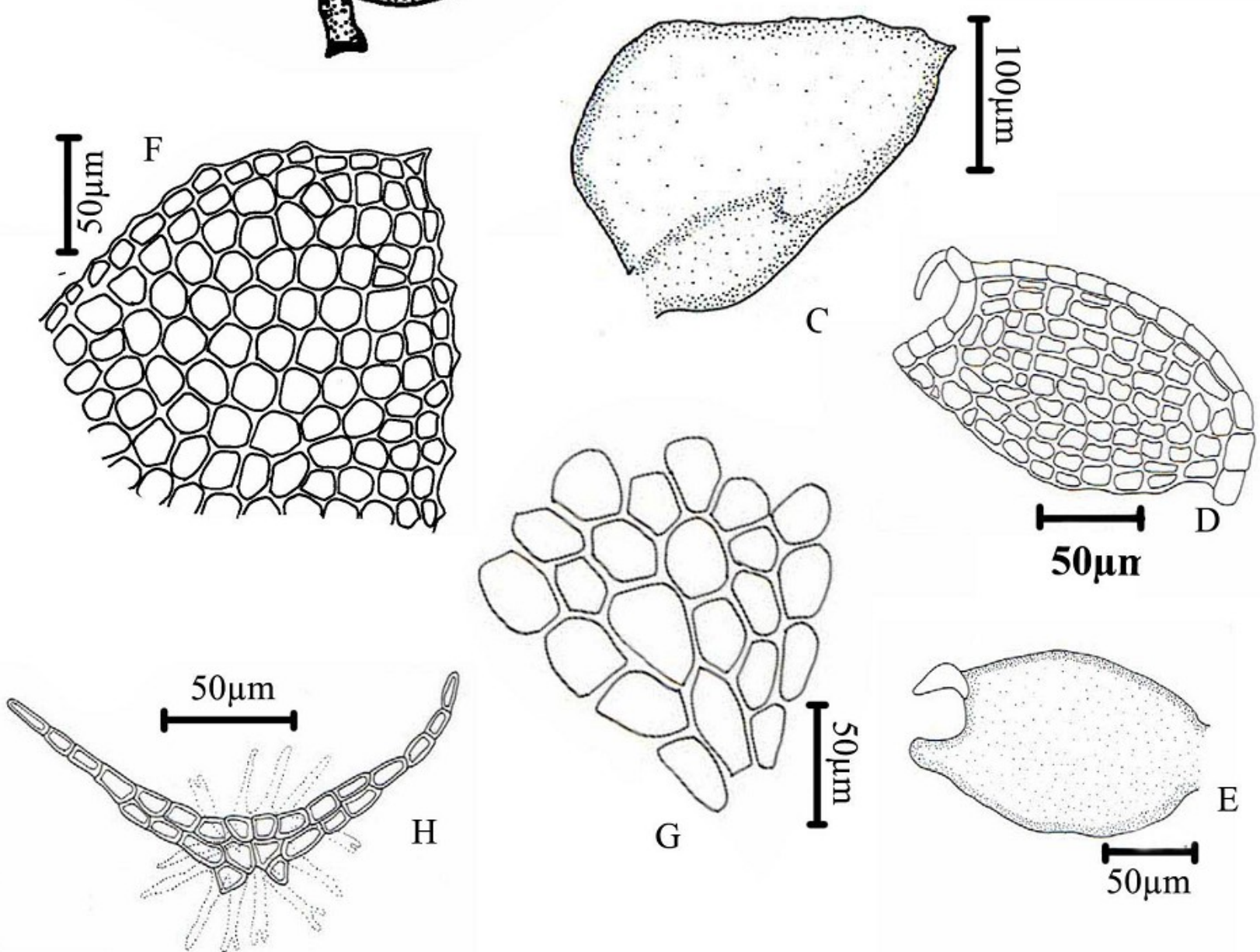

Fig. 7 (A-H). Drepanolejeunea fleischeri (Steph.) Grolle \& R. L. Zhu, A. portion of plant ventral view, B. female plant with perianth, C. single leaf, D \& E. leaf lobule, F. cells at leaf apex, G. leaf basal cells, H. under leaf. 

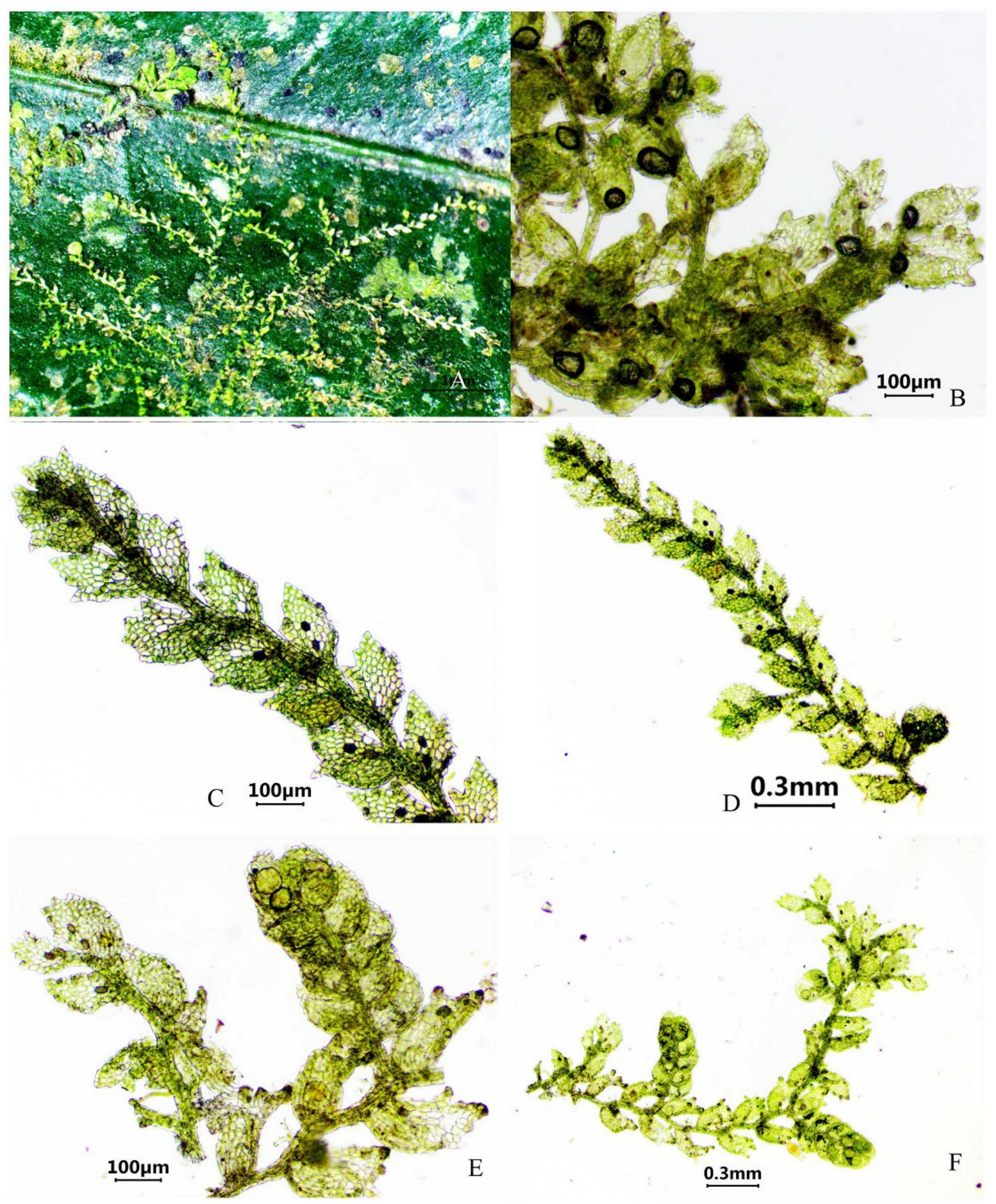

F

Fig. 8 (A-F). Drepanolejeunea pentadactyla (Mont.) Steph., A \& B. habit, C \& D. single plant dorsal view, E \& F. male plant with antheridium.

and three medullary cells; ventral merophytes 2 cells wide; rhizoids present at the base of underleaves, few, tufted, hyaline, rhizoidal disc absent; leaves contiguous, distant, diverging from stem at an angle of $41-54^{\circ}$, leaf lobe oblonglanceolate to elliptic, $0.18-0.25 \times 0.09-0.13 \mathrm{~mm}$, apex acute, margin with 5 tooth, rarely 3, teeth 2-3 cells long, 2-3 cells wide, each teeth with the apical cells acuminate and subquadrate, thin walled, 13.6-
$22.68 \times 5.90-10.25 \mu \mathrm{m}$, median cells rectangular to hexagonal, 16-28 $\times 9.15 \mu \mathrm{m}$, basal cells elongated rectangular, $30-42 \mu \mathrm{m}$, trigones and intermediate nodular thickenings absent, ocelli present in some leaves, if present two in number, not seriate, separated by one normal leaf cell; leaf lobule dimorphic, reduced lobules 0.07-0.09×0.02-0.04 $\mathrm{mm}, 4-5$ cells long along the margin with two layer cells long, large lobules inflated, ovate, $1 / 2$ to $3 / 4^{\text {th }}$ as 

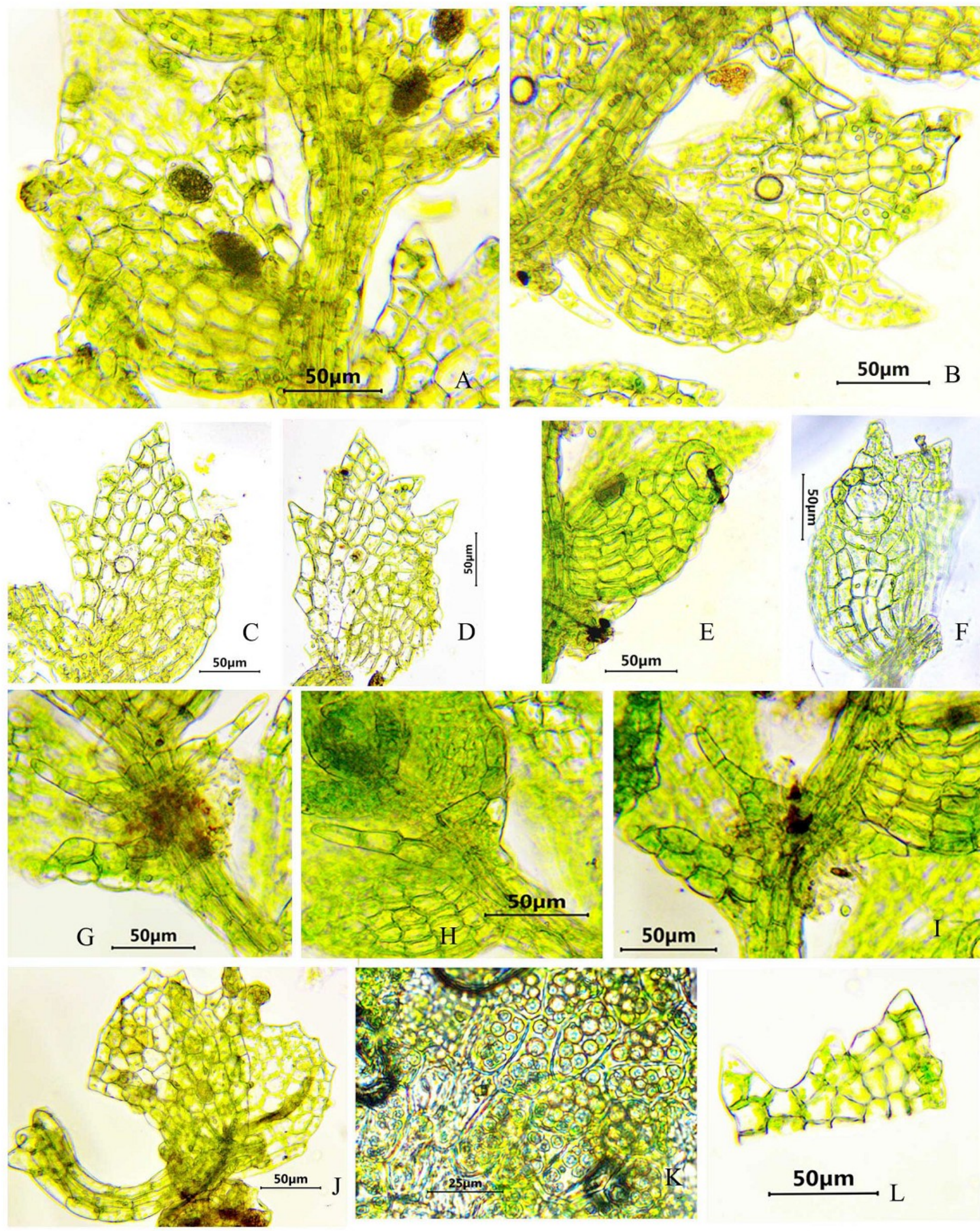

$50 \mu \mathrm{m}$

Fig. 9 (A-L). Drepanolejeunea pentadactyla (Mont.) Steph., A. leaf with ocelii, B. leaf with lobule, C\& D. single leaf, E \& F. inflated lobule, G, H \& I. underleaf and reduced leaf lobule, J. Perianth, K. leaf cell with oil bodies, L. leaf apex with teeth.

long as leaf lobe, $0.10-0.13 \times 0.06-0.09 \mathrm{~mm}$ wide, lateral margin of lobule bordered by 4 rectangular cells, 15-25 × 9-11 $\mu \mathrm{m}$, first tooth large, single hook shaped cell, 22-24 $\mu \mathrm{m}$, hyaline papilla present on the proximal base of the first tooth, second tooth indistinct, keel arched, serrated; underleaves bilobed, distant, one underleaf for each pair of leaf lobes, 0.03-0.05 $\mathrm{mm}$ long, $0.12-0.14 \mathrm{~mm}$ wide, 3 times wide as stem, lobes uniseriate, 2 -3 cells long, 2 cells wide at base, spreading, $80-100^{\circ}$ angle with stem.

Dioecious, androecia capitate, on short lateral branches, 2-5 pairs of bracts, imbricate, antheridium globular, $60-62.5 \mu \mathrm{m}$ in diameter, bracteoles rarely 


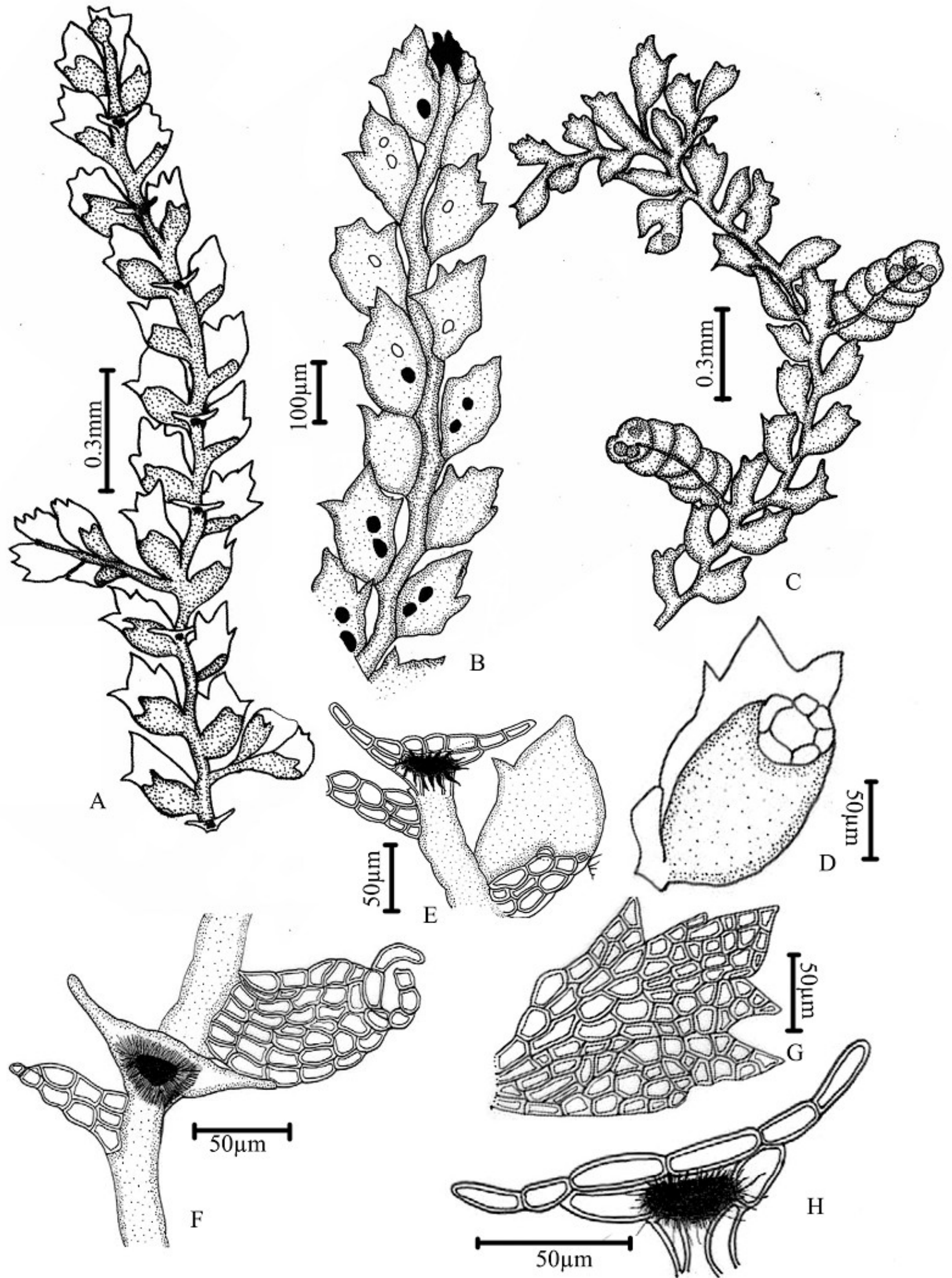

Fig. 10 (A-H). Drepanolejeunea pentadactyla (Mont.) Steph., A. portion of plant ventral view, B. plant dorsal view, C. male plant dorsal view, D. leaf with lobule, E \& F. leaf lobule and underleaf, G. single leaf, H. under leaf.

one or absent, position of gynoecia not clearly identified because of the rare occurrence of female reproductive structures, only fragmented and immature form of perianth is observed, perianth serrated, $0.16 \times 0.13 \mathrm{~mm}$, female bract same as leaf lobe, cells polygonal in shape, 15-22 $\mu \mathrm{m}$. (Fig. 8-10).

Specimens examined: India, Kerala, Palakkad, Parambikulam Tiger Reserve, on the way to Karimala 

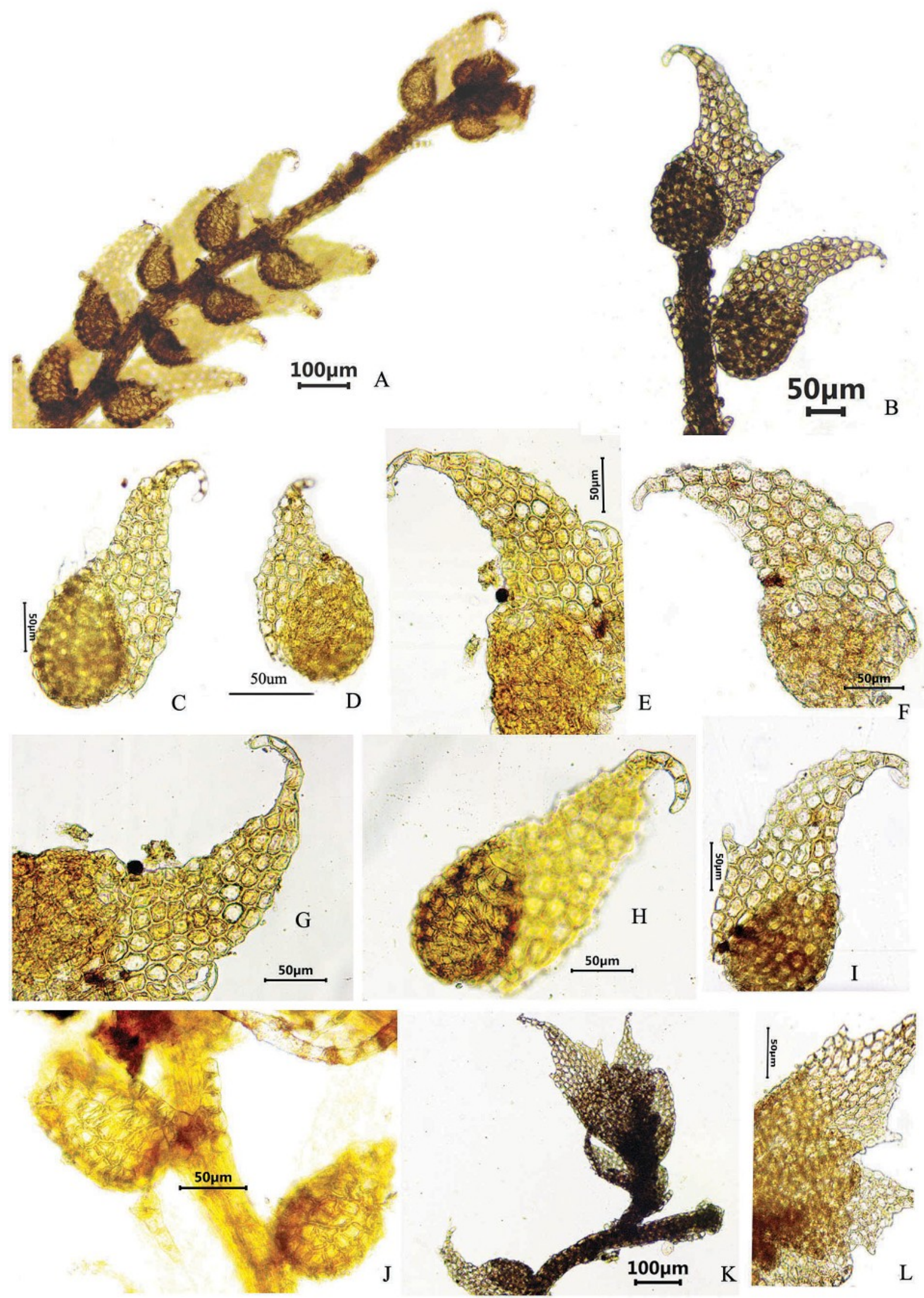

Fig. 11 (A-L). Drepanolejeunea ternatensis (Gottsche) Steph., A. portion of plant with cauducous leaves, B. leaves attached to stem, C-G. leaf lobes, H \& I. leaf lobule and involute leaf apex, J. stem with underleaf, K. perianth, L. Perianth cells enlarged view.

(1110 m, 10²7’59”N 76053'42”E) 05. 12. 2019 Chandini \& Sajitha 11028, 11029b, 11032 d, 11033 (ZGC).
Habitat: Epiphyllous, growing along with Cololejeunea truncatifolia (Horik.) Mizut., 


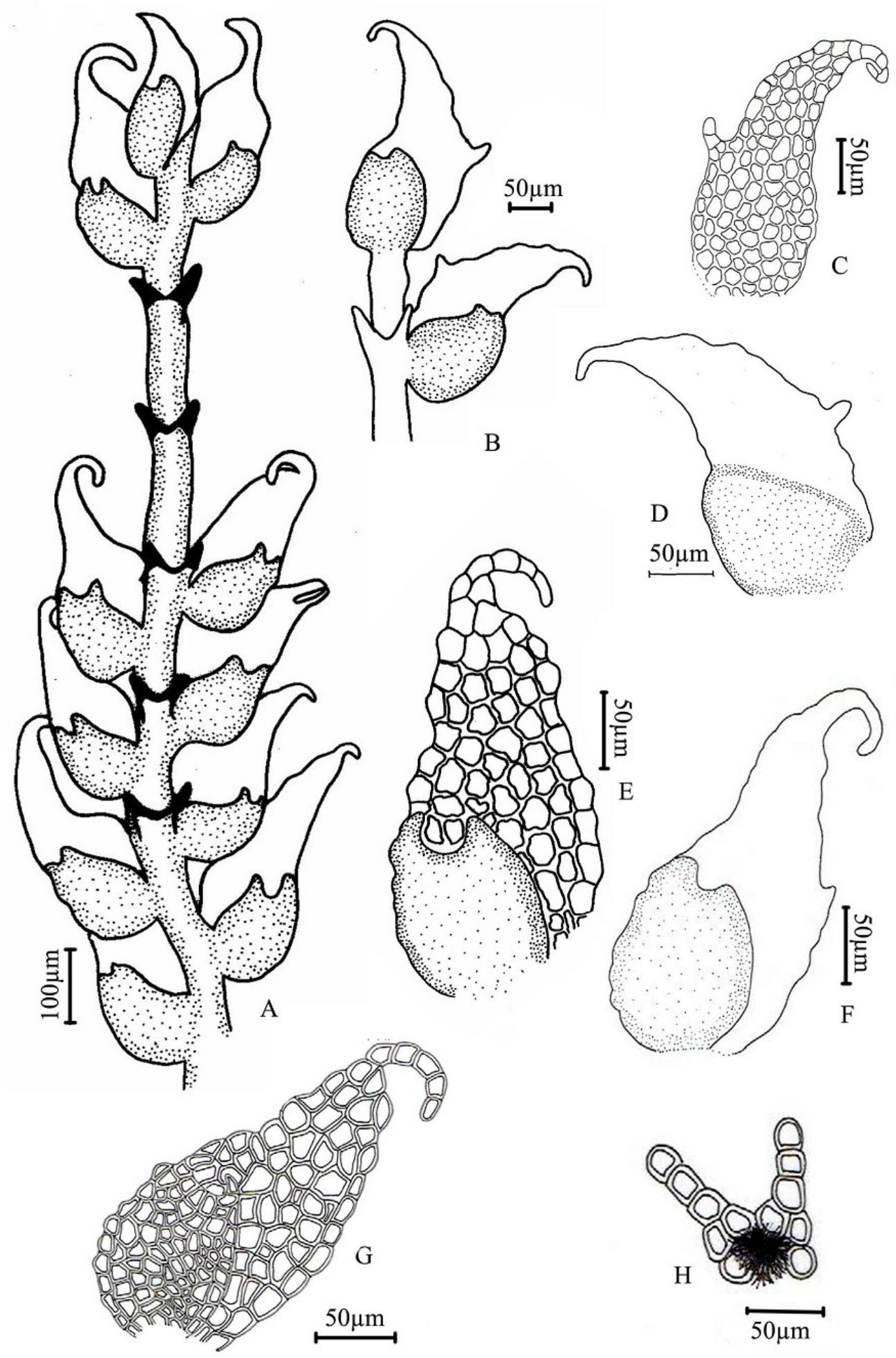

Fig. 12 (A-H). Drepanolejeunea ternatensis (Gottsche) Steph., A. plant ventral view with caducous leaf, B. portion of stem ventral view, C \& D. leaf dorsal view, E-G. different view of leaf lobule with unerleaf, H. Underleaf.

Drepanolejeunea fleischeri (Steph.) Grolle \& Zhu. and Leptolejeunea latifolia (Herzog) R.M. Schust.

Distribution: World; Africa (32), Cambodia (24), China (7), Indonesia (33), Japan (32), Malaysia (33), Vietnam (24), Papua New Guinea (11), Philippines
(12), Sri Lanka (30), Taiwan (26), Thailand (34), India; Andaman Nicobar (35), Nagaland (9); Western Ghats; [Karnataka, Kudremukh (31), Kerala (Present Collection). The present collection is a new record to Kerala. 
Drepanolejeunea ternatensis (Gottsche) Steph., Hedwigia 28: 169. 1889; A.E.D. Daniels, Arch. Bryo 65: 13. 2010; A.E.D. Daniels \& P. Daniel, Bryofl. S. W. Ghats. India: 147. 2013; A.E.D.Daniels \& Kariyappa, Bryo. Agasthyamalai Bio. Res.: 490. 2019. Lejeunea ternatensis Gottsche in Gottsche et al., Syn. Hepat. 346. 1845. Drepanolejeunea ternatensis (Gottsche) Steph. var. lancispina Herzog, Ann. Bryol. 12: 119. 1939; Udar \& Awasthi, J. Hattori Bot. Lab. 53: 430 1982; A.K. Asthana \& S.C. Srivasthava, Pl. Sci. Today 2 (4): 185.2015.

Type: Indonesia, Java (JE).

Plant light green, brown when dried, small, 1.15-3 $\times$ 0.23-0.28 mm including leaves, deeply appressed to the substratum; branching irregular, rhizoids few, hyaline; ventral merophytes two cells wide; stem c.s. with 7 cortical cells and 3 medullary cells; leaves distant, diverging from stem at $35-40^{\circ}$ angle, caducous, linear lanceolate, 0.24-0.3 × 0.10-0.12 mm, margin falcate, dorsal margin convex, irregularly toothed, tooth with 1-2 celled, ventral margin arched, serrated, apex acuminate, uniseriate at extreme tip, 4-6 cells long, curled towards dorsal margin, $19-20 \times 7 .-9 \mu \mathrm{m}$, marginal cells papillate, rounded-quadrate, $23-31 \times 14-15 \mu \mathrm{m}$, basal cells of toothed margin of leaf lobe elongated, $36.74 \times 76.88$ $\mu \mathrm{m}$, basal and median cells quadrate to rounded, 20$40 \times 15-20 \mu \mathrm{m}$, trigones and intermediate thickenings are present throughout the cells; leaf lobule inflated, ovate $0.05-0.1 \times 0.04-0.10 \mathrm{~mm}$, ovate, involute at margin, first tooth distinct, second one indistinct; underleaves bilobed, 0.05-0.07 × 0.03-0.04 $\mathrm{mm}$, sinus as wide as stem, 3 cells long, $0.04 \mathrm{~mm}$ long, attached with two lateral cells on each side, 6 marginal cells encircling the stem attachment area, cells circular, polygonal, 9-14 $\mu \mathrm{m}$.

Androecia is no seen, perianth is present on short lateral innovation, lobes toothed, 2-3 cells long, margin serrated, cells $29-34 \mu \mathrm{m}$, perianth lobe up to $0.35 \mathrm{~mm}$ long, male and other asexual reproductive structures are not seen (Fig. $11 \& 12$ ).

Specimens examined: India, Kerala, Idukki, Anamudi shola National Park (1697 m, 10²12'21”N 77011'09”E), 31.01.2016 Manju, A.C. 10227 (ZGC).

Habitat: Epiphytic on bark.

Distribution: World; Australia (36), Africa (37), China (24), Japan (8), Fiji, Indonesia (38), Malaysia (34 as D. ternatensis var. lancispina), New Caledonia (39), Papua New Guinea (11), Philippines (12), Taiwan (26), India; Western Ghats [Tamil Nadu: Nilgiri, on the way to Avalanche (5), Doddabetta (5, as D. ternatensis var. lancispina), Kanyakumari, Upper Kodaiyar (40), Palani Hills, Kodaikanal, Coasan road (42, as D. ternatensis var. lancispina), Kerala, Idukki, Anamudi Shola NP (Present collection)]. The present collection is a new distributional record to Kerala.

\section{Conclusion}

The present study records new distribution of four species in the Western Ghats part of Kerala viz., Drepanolejeunea ternatensis (Gottsche) Steph., D. fleischeri (Steph.) Grolle \& Zhu, D. pentadactyla
(Mont.) Steph. and D. erecta (Steph.) Mizut. Drepanolejeunea erecta was previously reported only from Eastern Himalayas. The study also found that most of the species occur at high altitudes above 1000 $\mathrm{m}$ MSL. Among these, Drepanolejeunea angustifolia (Mitt.) Grolle is distributed only above $2000 \mathrm{~m}$. Drepanolejeunea yunnanensis (P.C. Chen) Grolle \& R.L., Zhu is another species distributed in the Western Ghats of Karnataka. But the species is not yet reported from Kerala, hence, only five species have been dealt with here.

\section{Acknowledgements}

The authors are thankful to the authorities of the Zamorin's Guruvayurappan College for facilities and encouragement. The financial assistance from Kerala State Council for Science \& Technology and Environment (KSCSTE), Thiruvananthapuram, is gratefully acknowledged. We thank Dr. Tamas Pócs, Hungary, for the valuable suggestions and confirmation of some of our collections. We sincerely acknowledge the Kerala State Forest Department for permission and help in the field.

\section{Authors' contributions}

CVK collected most of the specimens from different localities of Kerala and prepared illustration and contributed for the preparation of manuscript. MB collected some specimens and prepared some photo plates and contributed for the preparation of manuscript. MCN collected some specimens for the study, prepared the photo plates and contributed for the preparation of manuscript and the mentor of first two authors. KPR collected some specimens and given comments on the manuscript.

\section{Conflict of interests}

The authors declare no competing interests.

\section{References}

1. Spruce R. Hepaticae of the Amazon and Andes of Peru and Ecuador. Trans Proc Bot Soc. Edinburgh 1884;15:1-308.

2. Schiffner V. Hepaticae (Lebermoose). In: A. Engler \& K. Prantl, Die natürl. Pflanzenfam. 1893;1(3):3-141. Engelmann, Leipzig.

3. Gradstein SR. A classification of Lejeuneaceae based on molecular and morphological evidence. Phytotaxa 2013;100:620. https://doi.org/10.11646/phytotaxa.100.1.2

4. Söderström L, Hagborg A, Konrat MV, Bartolomew-Began S Bell D, Briscoe L, Brown E, Cargill DC, Costa DP, CrandallStotler BJ, Cooper ED, Dauphin G, Engel JJ, Feldberg K, Glenny D, Gradstein SR, He X, Heinrichs J, Hentschel J, Ilkiu-Borges AL, Katagiri T, Konstantinova NA, Larrain J, Long DG, Nebel M, Pócs T, Puche F, Reinerdrehwald E, Renner MAM, SassGyarmati A, Schäfer-verwimp A, Moragues JGS, Stotler RE, Sukkharak P, Thiers BM, Uribe J, Văňa J, Villarreal JC, Wigginton M, Zhang L, Zhu RL. World check list of hornworts and liverworts. Phytokeys 2016;59:1-828. https://doi.org/10.3897/phytokeys.59.6261

5. Udar R, Awasthi US. The genus Drepanolejeunea St. in India. J Hattori Bot Lab. 1982;53:419-37.

6. Long DG, Grolle R. Hepaticae of Bhutan II. J Hattori Bot Lab. 1990; 68:381- 40. 
7. Piippo S. Annotated catalogue of Chinese Hepaticae and Anthocerotae. J Hattori Bot Lab. 1990;68:1-192.

8. Yamada K, Iwatsuki Z. Catalogue of the Hepaticae of Japan. J Hattori Bot Lab. 2006;99:1-106.

9. Singh DK, Singh SK, Singh D. Liverworts and Hornworts of India, An annotated Checklist. Botanical Survey of India, 2016.

10. Pradhan N, Joshi SD. Liverworts and hornworts of Nepal: a synopsis. Bot Or J Plant Sci. 2009;6:69-75. https://doi.org/10.3126/botor.v6i0.2913

11. Grolle R, Piippo S. Annotated catalogue of Western Melanesian bryophytes. I. Acta Bot Fennici 1984;125:1-86.

12. Tan BC, Engel JJ. An annotated checklist of Philippine Hepaticae. J Hattori Bot Lab. 1986;60:283-355.

13. Dey M, Singh D, Singh DK. The genus Drepanolejeunea (Marchantiophyta: Lejeuneaceae) in India with a note on three new additions from Eastern Himalaya. Trop Bryol. 2013; 35: 14-25. https://doi.org/10.11646/bde.35.1.2

14. Singh DK, Singh SK, Dey M. On a Collection of Hepaticae from Andaman Islands. Phytotaxonomy 2006;6:99-104.

15. Rawat KK, Verma PK. On a Collection of Liverwort from Tawang, Arunachal Pradesh, India with Frullania rhystocolea Herzog new to India. Frahmia 2014;8:1-7.

16. Singh AP, Nath V. Hepaticae of Khasi and Jaintia Hills: Eastern Himalayas. Bishen Singh Mahendra Pal Singh, Dehra Dun. 2007; pp. 382.

17. Mitten W. Hepaticae Indiae Orientalis, An enumeration of the Hepaticae of East Indies. J Linn Soc. 1861;5:89-128.

18. Dey M, Singh DK. Epiphyllous Liverworts of Eastern Himalaya. Botanical Survey of India, Kolkata; 2012.

19. Mizutani M. On some Indian species of the family Lejeuneaceae described by W. Mitten. J Hattori Bot Lab. 1963;26:171-84.

20. Udar R, Awasthi US. A new species of Leptolejeunea from India. Misc Bryol Lichenol. 1979;8:115-17.

21. Manju CN, Pocs T, Rajesh KP, Prakashkumar R. Lejeuneaceae (Marchantiophyta) of the Western Ghats, India. Acta Biol Plant Agr. 2012;2:125-45.

22. Manju CN, Rajesh KP, Madhusoodanan PV. Checklist of the bryophytes of Kerala India. Trop Bryol Res Rep. 2008;7:1-24

23. Furuki, T. and Mizutani, M. 1994. Checklist of Japanese Hepaticae and Anthocerotae, 1993. Proc Bryol Soc Japan 6:7583

24. Zhu R-L, So ML. Epiphyllous liverworts of China. Nova Hedwig Beih. 2001;121:1-418.

25. Zhu RL, Long DG. Lejeuneaceae (Hepaticae) from several recent collections from the Himalaya. J Hattori Bot Lab. 2003;93:101-15

26. Wang J, Lai M-J, Zhu R-L. Liverworts and hornworts of Taiwan: an updated checklist and floristic accounts. Ann Bot Fenn. 2011;48:369-95.

27. Dey M, Singh D, Singh DK. Some new and noteworthy records of hepaticae from Eastern Himalaya, India. Indian J For. 2009;32:669- 84 .

28. Singh D, Dey M, Upadhyay GK. A preliminary survey of Hepaticae of little Andaman Island. Nelumbo 2010;52:125-30.
29. Hattori S. Bryophyta. In: Hara, H. (editor), The Flora of Eastern Himalaya. University of Tokyo, Japan. 1966;501-36.

30. Long DG, Rubasinghe SCK. Liverworts and hornworts of Sri Lanka: a revised Checklist. Ceylon J Sci. (Bio Sci.) 2014; 43(1):136.

31. Asthana G, Shukla A. Two epiphyllous species of Drepanolejeunea (Spruce) Schiffn. new to the Indian bryoflora. J Bryol. 2009;31:139-42. https://doi.org/10.1179/037366809X400419

32. Pocs T. East African bryophytes XXIX. The Ceratolejeunea (Lejeuneaceae) species of the Indian ocean islands. Polish Bot J. 2011;56 (2):131-53.

33. Chuah-Petiot MS. A checklist of Hepaticae and Anthocerotae of Malaysia. Polish Bot J. 2011;56:1-44.

34. Lai MJ, Zhu R-L. Chantanaorrapint S. Liverworts and hornworts of Thailand: an updated checklist and bryofloristic accounts Ann Bot Fennici. 2008; 45:321-41. https://doi.org/10.5735/085.045.0501

35. Dey M, Singh DK. Three foliicolous species of Lejeuneaceae (Marchantiophyta) new to India from Great Nicobar Biosphere Reserve, Andaman and Nicobar Islands. Acta Bot Hung. 2016;58(1-2):49-68. https://doi.org/10.1556/034.58.2016.1-2.2

36. McCarthy, P.M. 2006. Checklist of Australian liverworts and hornworts. Australian Biological Resources Study, Canberra. Version 6 April 2006.

37. Söderström L, Gradstein SR, Hagborg A. Checklist of the hornworts and liverworts of Java. Phytotaxa 2010;9:53-149.

38. Söderström L, Hagborg A, Pocs T, Sass-Gyarmati A, Brown E, von Konrat M, Renner M. Checklist of hornworts and liverworts of Fiji. Telopea 2011;13:405-54.

39. Thouvenot L, Gradstein SR, Hagborg A, Söderström L, Bardat J. Checklist of the liverworts and hornworts of New Caledonia. Cryptogamie, Bryologie 2011;32:287-390. https://doi.org/10.7872/cryb.v32.iss4.2011.287

40. Daniels AED, Daniel P. The bryoflora of the Southernmost Western Ghats, India. Bishen Singh Mahendra Pal Singh, Dehra Dun. 2013; pp.352.

41. Daniels AED, Kariyappa KC, Bryoflora of the Agasthyamalai Biosphere Reserve, Western Ghats, India. Bishen Singh Mahendra Pal Singh, Dehra Dun. 2019; pp. 658.

42. Singh SK, Dey M, A new species of Drepaolejeunea (Marchantiophyta: Lejeuneaceae) from India. Nelumbo 2012;54:14-17.

43. Pandé SK, Srivastava KP, Ahmad S, Epiphyllous liverworts of India and Ceylon. II. J Ind Bot Soc., 1957;36(3):335-47.

44. Singh SK, Description of six new species and two new infraspecific taxa of Lejeuneaceae (Marchantiophyta) from India. Nelumbo 2018;60(1):69-84

45. Grolle R, Zhu RL, A study of Drepanolejeunea subg. Rhaphidolejeunea (Herzog) Grolle \& RL Zhu, stat. nov. (Hepaticae, Lejeuneaceae) in China with notes on its species elsewhere. Nov. Hedwig. 2000;70:373-96.

46. Udar R, Awasthi US, The genus Rhaphidolejeunea Hork. India Yushania 1984;1:15-17. 